\title{
Rheumatoid Arthritis Research in India: A Scientometric Assessment of Publications during 2007-2016
}

\author{
Gupta BM ${ }^{1}$, Ritu Gupta ${ }^{2}$, Ashok Kumar ${ }^{3}$ and Madhu Bansal ${ }^{4 *}$ \\ ${ }^{1}$ Formerly with National Institute of Science, Technology \& Development Studies, New Delhi \\ ${ }^{2}$ Formerly with Venkateswara University,, India \\ ${ }^{3}$ M.M.University, India \\ *Corresponding author: Ritu Gupta, Formerly with Venkateswara University, India
}

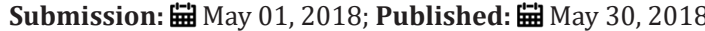

\begin{abstract}
The paper examines 1744 Indian publications on rheumatoid arthritis research, as covered in Scopus database during 2007-16, experiencing an annual average growth rate of $8.19 \%$ and qualitative citation impact averaged to 9.23 citations per paper. India's share in global output was $3.05 \%$ during 2007-16, which increased from 2.46\% to 3.61\% from 2007-11 to 2012-16. The international collaborative share of India's publications in rheumatoid arthritis research was $11.75 \%$ during $2007-16$, which increased from $11.35 \%$ to $12.02 \%$ from $2007-11$ to $2012-16$. Medicine, among subjects contributed the highest publications share (58.89\%) in India's output in rheumatoid arthritis,, followed by pharmacology, toxicology \& pharmaceutics (30.91\%), biochemistry, genetics \& molecular biology (18.41\%), immunology \& microbiology (12.10\%) and chemistry (3.44\%) during 2007-16.

The top 15 most productive organizations and authors together contributed $29.87 \%$ and $18.23 \%$ respectively as their share of global publication output and $37.92 \%$ and $22.36 \%$ respectively as their share of global citation output during 2007-16. Among the total journal output of 1722 papers (98.74\% of total output), the top 15 journals contributed $31.24 \%$ share to the global journal output in rheumatoid arthritis research in India during 2007-16, which increased from $30.41 \%$ to $31.79 \%$ from $2007-11$ and 2012-16. Indian Journal of Radiology contributed the largest number of papers (169), followed by International Journal of Rheumatic Diseases (50 papers), Rheumatology International (36 papers), Clinical Rheumatology (30 papers), etc. during 2007-16. Of the total Indian rheumatoid arthritis research output, the top 12 highly cited publications registered citations from 101 to 1138 during 2007-16, which together received 3405 citations, which averaged to 283.78 citations per paper.
\end{abstract}

Keywords: Rheumatoid arthritis research; Indian publications; Scientometrics; Bibliometrics

\section{Introduction}

Rheumatoid arthritis (RA) is an autoimmune disease in which the body's immune system-which normally protects its health by attacking foreign substances like bacteria and viruses-mistakenly attacks the joints. This creates inflammation that causes the tissue that lines the inside of joints (the synovium) to thicken, resulting in swelling and pain in and around the joints. The synovium makes a fluid that lubricates joints and helps them move smoothly. Rheumatoid arthritis most commonly affects the joints of the hands, feet, wrists, elbows, knees and ankles. The joint effect is usually symmetrical. That means if one knee or hand if affected, usually the other one is, too. Because RA also can affect body systems, such as the cardiovascular or respiratory systems, it is called a systemic disease. Systemic means "entire body" [1]. RA affects about 24.5 million people as of 2015 [2]. This is between 0.5 and $1 \%$ of adults in the developed world with 5 and 50 per 100,000 people newly developing the condition each year [3] Onset is most frequent during middle age and women are affected 2.5 times as frequently as men [4]. In 2013, it resulted in 38,000 deaths up from 28,000 deaths in 1990 [5].

Rheumatoid arthritis (RA) affects about $0.92 \%$ of adult population in India. Early diagnosis and aggressive therapy can usually prevent permanent disability. This, unfortunately, does not happen in many cases. There are about 20-40 new cases per Lac population each year and the disease occurs more frequently in females. The onset can be after delivery although the disease remains silent during pregnancy. Stress and environmental triggers can precipitate onset of the disease. About 5\% of first degree relatives are at risk of developing RA. Cigarette smoking, coffee and 
oral contraceptive pills appear to increase risk of development of RA [6].

\section{Literature Review}

Only one study has so far been conducted in the past on quantitative analysis of arthritis research. Lewison \& Devey [7] used bibliometric methods to evaluate the magnitude and quality of publications in arthritis research in the UK and also compared this with that of other countries. Outputs from 13 countries between 1988 and 1995 were analyzed by number, research level (from clinical to basic) and potential impact on other researchers (from low to high). The UK has a strong presence in arthritis research and the highest relative commitment of all the countries studied. Papers with funding acknowledgements were of significantly higher impact and less clinical than those without. Only one literature review is available on rheumatoid arthritis research in India. Here Handa et al. [8] provided a literature review of observational studies published from 1985 to 2012 and this review identified twentyeight studies. Of the 28 studies, seven described the descriptive epidemiology of RA, 14 described comorbidities and extra-articular manifestations, nine described the functioning abilities and quality of life among patients, and 10 provided information on treatments. Since no Indian bibliometric study was available in this area, as a result we decided to undertake the present study.

\section{Objectives}

The main objectives of this study are to study the performance of India's rheumatoid arthritis research during 2007-16, based on publications output covered in Scopus database. In particular, the study focuses on the following objectives:

i. To study the growth India's research output in rheumatoid arthritis research and its citation impact ;

ii. To study the India's international collaboration share and share of leading collaborating countries

iii. To study the Indian research output by broad subject areas

iv. To study the publication productivity and citation impact of top 15 most productive organizations and authors

v. To study the modes of communication and identification of most productive journals and

(v) to study the characteristics of top 12 highly cited papers.

\section{Methodology}

The study retrieved and downloaded 10-yearpublication data of the Indian output in rheumatoid arthritis research from the Scopus database (http://www.scopus.com) covering the period 2007-16. Keywords, such as "rheumatoid arthritis" were searched in "keyword tag" or "Ärticle Title tag" for period 2007-16 within "date range tag". This became our main search string. When the main search string was restricted to "India tag", we were able to get publication data on India, which consisted of 1744 publications. Using analytical commands or tags available in Scopus database, such as "subject area tag", "country tag", "source title tag", "journal title name" and "affiliation tag", we were able to get data/information on the distribution of publications output by subject, collaborating countries, author-wise, organization-wise and journal-wise, etc. For citation data, citations to publications were also collected from date of publication till July 2017.

((KEY(rheumatoid arthritis) OR TITLE(rheumatoid arthritis)) AND PUBYEAR > 2006 AND PUBYEAR $<2017$

(KEY(rheumatoid arthritis) OR TITLE(rheumatoid arthritis)) AND PUBYEAR > 2006 AND PUBYEAR < 2017 AND ( LIMIT-TO ( AFFILCOUNTRY,"India") )

\section{Analysis}

Table 1: World and India's output in rheumatoid arthritis research, 2007-16.

\begin{tabular}{|c|c|c|c|c|c|c|c|}
\hline \multirow{2}{*}{$\begin{array}{l}\text { Publication } \\
\text { Period }\end{array}$} & \multirow{2}{*}{$\begin{array}{c}\text { World } \\
\text { TP }\end{array}$} & \multicolumn{6}{|c|}{ India } \\
\hline & & TP & TC & CPP & ICP & \%ICP & $\%$ ТP \\
\hline 2007 & 5243 & 92 & 1574 & 17.11 & 4 & 4.35 & 1.75 \\
\hline 2008 & 5187 & 102 & 1444 & 14.16 & 15 & 14.71 & 1.97 \\
\hline 2009 & 5664 & 119 & 2018 & 16.96 & 18 & 15.13 & 2.1 \\
\hline 2010 & 5803 & 156 & 2976 & 19.08 & 20 & 12.82 & 2.69 \\
\hline 2011 & 6043 & 218 & 2035 & 9.33 & 21 & 9.63 & 3.61 \\
\hline 2012 & 6300 & 230 & 1904 & 8.28 & 23 & 10 & 3.65 \\
\hline 2013 & 6466 & 246 & 1551 & 6.3 & 27 & 10.98 & 3.8 \\
\hline 2014 & 6213 & 216 & 1086 & 5.03 & 29 & 13.43 & 3.48 \\
\hline 2015 & 5840 & 200 & 1316 & 6.58 & 26 & 13 & 3.42 \\
\hline 2016 & 4429 & 165 & 200 & 1.21 & 22 & 13.33 & 3.73 \\
\hline $2007-11$ & 27960 & 687 & 10047 & 14.62 & 78 & 11.35 & 2.46 \\
\hline $2012-16$ & 29248 & 1057 & 6057 & 5.73 & 127 & 12.02 & 3.61 \\
\hline $2007-16$ & 57208 & 1744 & 16104 & 9.23 & 205 & 11.75 & 3.05 \\
\hline
\end{tabular}


The total research output of the world and India in field of rheumatoid arthritis cumulated is 57208 and 1744 publications in 10 years during 2007-16. The annual output of the world and India in rheumatoid arthritis research increased from 5243 and 92 in the year 2007 to 4429 and 165 publications in the year 2016, registering-1.39\% and $8.19 \%$ growth per annum. The cumulative world and Indian output inrheumatoid arthritis research in 5 years 2007-11 increased from 27960 and 687 to 29248 and 1057 publications during succeeding 5-year period 2012-16, registering $4.61 \%$ and $53.86 \%$ quinquennial growth. India's share in global publication output in rheumatology arthritis was 3.05\% during 2007-16, which increased from $2.46 \%$ to $3.61 \%$ from $2007-11$ to 2012-16.Of the total Indian publications output on arthritis, $62.04 \%$ (1082) was published as articles, $23.74 \%$ (414) as reviews, $6.77 \%$ (118) as letters, $3.04 \%$ (53) as editorials, $1.83 \%$ (32) as conference papers, $1.43 \%$ (25) as notes and the rest as book chapters (5) and erratum (1). The citation impact of Indian publications on arthritis research averaged to 9.23 citations per publication (CPP) during
2007-16; five-yearly impact averaged to 14.62CPP for the period 2007-11 which declined to 5.73CPP in the succeeding five-year 2012-16 (Table 1).

\section{India's international collaboration}

The international collaborative share of India's publications in rheumatoid arthritis research was $11.75 \%$ during 2007-16, which increased from $11.35 \%$ to $12.02 \%$ from $2007-11$ to 2012 16. Among foreign countries, USA contributed the largest share of $47.80 \%$ to India's international collaborative papers in arthritis research, followed by U.K. (22.44\%), France (12.20\%), Germany (10.24\%), Japan (9.76\%), Italy and Netherlands (7.80\% each), Canada and Sweden (7.32\% each) and Argentina (6.83\%) during 2007-16. The share of international collaborative papers increased by $7.47 \%$ in Japan, followed by $6.19 \%$ in Germany, $3.11 \%$ in U.K., $2.25 \%$ each in Italy and Netherlands, $1.46 \%$ in Sweden and $0.68 \%$ in Argentina, as against decrease by $7.68 \%$ in USA, 3.08\% in France and $0.61 \%$ in Canada from 2007-11 to 2012-16 (Table 2).

Table 2: The share of top 10 foreign countries in India's international collaborative papers in rheumatoid arthritis research during 2007-16.

\begin{tabular}{|c|c|c|c|c|c|c|c|}
\hline \multirow{2}{*}{ S.No. } & \multirow{2}{*}{$\begin{array}{l}\text { Collaborative } \\
\text { Country }\end{array}$} & \multicolumn{3}{|c|}{ Number of International Collaborative Papers } & \multicolumn{3}{|c|}{ Share of International Collaborative Papers } \\
\hline & & 2007-11 & 2012-16 & 2007-16 & 2007-11 & 2012-16 & 2007-16 \\
\hline 1 & USA & 41 & 57 & 98 & 52.56 & 44.88 & 47.8 \\
\hline 2 & U.K. & 16 & 30 & 46 & 20.51 & 23.62 & 22.44 \\
\hline 3 & France & 11 & 14 & 25 & 14.1 & 11.02 & 12.2 \\
\hline 4 & Germany & 5 & 16 & 21 & 6.41 & 12.6 & 10.24 \\
\hline 5 & Japan & 4 & 16 & 20 & 5.13 & 12.6 & 9.76 \\
\hline 6 & Italy & 5 & 11 & 16 & 6.41 & 8.66 & 7.8 \\
\hline 7 & Netherlands & 5 & 11 & 16 & 6.41 & 8.66 & 7.8 \\
\hline 8 & Canada & 6 & 9 & 15 & 7.69 & 7.09 & 7.32 \\
\hline 9 & Sweden & 5 & 10 & 15 & 6.41 & 7.87 & 7.32 \\
\hline \multirow[t]{2}{*}{10} & Argentina & 5 & 9 & 14 & 6.41 & 7.09 & 6.83 \\
\hline & Total & 78 & 127 & 205 & 100 & 100 & 100 \\
\hline
\end{tabular}

\section{Subject-wise distribution of research output}

The global rheumatoid arthritis research output published during 2007-16is distributed across five sub-fields (as identified in Scopus database classification), with medicine science accounting for the highest publications share (58.89\%), followed by pharmacology, toxicology \& pharmaceutics (30.91\%), biochemistry, genetics \&molecular biology (18.41\%), immunology \&microbiology (12.10\%) and chemistry (3.44\%) during 2007-16. The activity index, which computes change in research activity in a discipline over time 2007-11 to 2012-16 (world average activity index of a

Table 3: Subject-wise breakup of Indian publications in rheumatoid arthritis research during 2007-16.

\begin{tabular}{|c|c|c|c|c|c|c|c|c|c|}
\hline \multirow{2}{*}{ S.No } & Subject* & \multicolumn{2}{|c|}{ Number of Papers (TP) } & \multicolumn{2}{c|}{ Activity Index } & TC & CPP & \%TP \\
\cline { 2 - 11 } & & $\mathbf{2 0 0 7 - 1 1}$ & $\mathbf{2 0 1 2 - 1 6}$ & $\mathbf{2 0 0 7 - 1 6}$ & $\mathbf{2 0 0 7 - 1 1}$ & $\mathbf{2 0 1 2 - 1 6}$ & $\mathbf{2 0 0 7 - 1 6}$ & $\mathbf{2 0 0 7 - 1 6}$ & $\mathbf{2 0 0 7 - 1 6}$ \\
\hline 1 & Medicine & 485 & 542 & 1027 & 119.88 & 87.08 & 9523 & 9.27 & 58.89 \\
\hline 2 & $\begin{array}{c}\text { Pharmacology, toxicology \& } \\
\text { pharmaceutics }\end{array}$ & 189 & 350 & 539 & 89.01 & 107.14 & 5294 & 9.82 & 30.91 \\
\hline
\end{tabular}

given subject is taken as 100), witnessed increase in pharmacology, toxicology \& pharmaceutics (from 89.01 to 107.14), biochemistry, genetics \& molecular biology (from 97.78 to 107.94), immunology \& microbiology (from 96.25 to 102.44) and chemistry (from 80.39 to 112.75), as against decline of research activity in medicine (from 119.88 to 87.08),from 2007-11 to 2012-16. In terms of citation impact per paper, chemistry tops the list with CPP of 30.33, followed by immunology \& microbiology (13.89),biochemistry, genetics \& molecular biology (13.42), pharmacology, toxicology \& pharmaceutics (9.82) and medicine (9.27) during 2007-16 (Table 3). 


\begin{tabular}{|c|c|c|c|c|c|c|c|c|c|}
\hline 3 & $\begin{array}{c}\text { Biochemistry, genetics \& molecular } \\
\text { biology }\end{array}$ & 111 & 210 & 321 & 87.78 & 107.94 & 4309 & 13.42 & 18.41 \\
\hline 4 & Immunology \& microbiology & 80 & 131 & 211 & 96.25 & 102.44 & 2931 & 13.89 & 12.1 \\
\hline 5 & Chemistry & 19 & 41 & 60 & 80.39 & 112.75 & 1820 & 30.33 & 3.44 \\
\hline & World output & 687 & 1057 & 1744 & 100 & 100 & & \\
\hline \multicolumn{7}{|c|}{ TP: Total Papers; TC: Total Citations; CPP: Citations Per Paper } \\
\hline
\end{tabular}

\section{Profile of top 15 most productive Indian organizations}

In Indian rheumatoid arthritis research, the productivity of 15 most productive Indian organizations varied from 18 to 87 publications and together they contributed 29.87\% (521) publication share and $37.92 \%$ (6107) citation share to its cumulative publications output during 2007-16. The scientometric profile of these 15 organizations is presented in (Table 4). Four of these organizations registered publications output greater than the group average of 34.76: Sanjay Gandhi Postgraduate Institute of Medical Sciences (SGPGIMS), Lucknow (87 papers), All India Institute of Medical Sciences (AIIMS), New Delhi (80 papers), Postgraduate Institute of Medical Education \& Research (PGIMER), Chandigarh (76 papers) and Christian Medical College (CMC), Vellore (38 papers) during 2007-16. Six organizations registered impact above the group average of 11.72 citations per publication during 2007-16: All India Institute of Medical Sciences, New Delhi (20.35), Center for Rheumatic Diseases, Pune (17.40), Postgraduate Institute of Medical Education \& Research (PGIMER), Chandigarh (15.68), Aligarh Muslim University (15.41), Sanjay Gandhi Postgraduate Institute of Medical Sciences, Lucknow (13.51) and Banaras Hindu University, Varanasi (13.0) during 2007-16.Seven organizations registered h-index above the group average of 7.93: Sanjay Gandhi Postgraduate Institute of Medical Sciences, Lucknow (19), All India Institute of Medical Sciences, New Delhi (17), Postgraduate Institute of Medical Education \& Research, Chandigarh(11), Aligarh Muslim University and Punjabi University, Patiala (10 each), Center for Rheumatic Diseases, Pune and Banaras Hindu University, Varanasi (9 each) during 200716. Six organizations contributed international collaborative publications share above the group average of 13.05\%: Nizam's Institute of Medical Sciences, Hyderabad (28.57\%), Aligarh Muslim University (27.27\%), Jawaharlal Institute of Postgraduate Medical Education \& Research (JIPMER), Pondicherry (21.74\%), Christian Medical College, Vellore (21.05\%), Center for Rheumatic Diseases, Pune (20.0\%) and Institute of Post Graduate Medical Education \& Research, Kolkata (19.23\%) during 2007-16. Six organizations registered the relative citation index above the group average (1.27) of all organizations: All India Institute of Medical Sciences, New Delhi (2.20), Center for Rheumatic Diseases, Pune (1.89), Postgraduate Institute of Medical Education \& Research, Chandigarh (1.70), Aligarh Muslim University (1.67), Sanjay Gandhi Postgraduate Institute of Medical Sciences, Lucknow (1.46) and Banaras Hindu University, Varanasi (1.41) during 2007-16.

Table 4: Scientometric Profile of Top 15 most productive Indian organizations in rheumatoid arthritis research during 2007-16.

\begin{tabular}{|c|c|c|c|c|c|c|c|c|}
\hline S.No & Name of the Organization & TP & TC & CPP & HI & ICP & $\%$ ICP & RCI \\
\hline 1 & $\begin{array}{l}\text { Sanjay Gandhi Postgraduate Institute of Medical Sciences } \\
\text { (SGPGIMS), Lucknow }\end{array}$ & 87 & 1175 & 13.51 & 19 & 11 & 12.64 & 1.46 \\
\hline 2 & All India Institute of Medical Sciences (AIIMS), New Delhi & 80 & 1628 & 20.35 & 17 & 9 & 11.25 & 2.2 \\
\hline 3 & $\begin{array}{l}\text { Postgraduate Institute of Medical Education \& Research } \\
\text { (PGIMER), Chandigarh }\end{array}$ & 76 & 1192 & 15.68 & 11 & 8 & 10.53 & 1.7 \\
\hline 4 & Christian Medical College (CMC), Vellore & 38 & 154 & 4.05 & 6 & 8 & 21.05 & 0.44 \\
\hline 5 & Punjabi University, Patiala & 30 & 277 & 9.23 & 10 & 0 & 0 & 1 \\
\hline 6 & $\begin{array}{l}\text { Institute of Post Graduate Medical Education \& Research } \\
\text { (IPGMER), Kolkata }\end{array}$ & 26 & 123 & 4.73 & 4 & 5 & 19.23 & 0.51 \\
\hline 7 & Banaras Hindu University, Varanasi & 24 & 312 & 13 & 9 & 1 & 4.17 & 1.41 \\
\hline 8 & $\begin{array}{c}\text { Jawaharlal Institute of Postgraduate Medical Education \& } \\
\text { Research (JIPMER), Pondicherry }\end{array}$ & 23 & 123 & 5.35 & 4 & 5 & 21.74 & 0.58 \\
\hline 9 & Aligarh Muslim University & 22 & 339 & 15.41 & 10 & 6 & 27.27 & 1.67 \\
\hline 10 & Nizam's Institute of Medical Sciences (NIMS), Hyderabad & 21 & 123 & 5.86 & 6 & 6 & 28.57 & 0.63 \\
\hline 11 & Center for Rheumatic Diseases, Pune & 20 & 348 & 17.4 & 9 & 4 & 20 & 1.89 \\
\hline 12 & Medical College \& Hospital, Kolkata & 19 & 83 & 4.37 & 5 & 1 & 5.26 & 0.47 \\
\hline 13 & Armed Forces Medical College, Pune & 19 & 40 & 2.11 & 3 & 2 & 10.53 & 0.23 \\
\hline 14 & $\begin{array}{l}\text { Chhatrapati Shahuji Maharaj Medical University (CSMMU), } \\
\text { Lucknow }\end{array}$ & 18 & 64 & 3.56 & 4 & 2 & 11.11 & 0.39 \\
\hline 15 & Jamia Hamdard University, Delhi & 18 & 126 & 7 & 2 & 0 & 0 & 0.76 \\
\hline
\end{tabular}




\begin{tabular}{|c|c|c|c|c|c|c|c|}
\hline Total of 15 organizations & 521 & 6107 & 11.72 & 7.93 & 68 & 13.05 & 1.27 \\
\hline Total of India & 1744 & 16104 & 9.23 & & & & \\
\hline Share of top 15 organizations in Indian total output & 29.87 & 37.92 & & & & & \\
\hline
\end{tabular}

TP: Total Papers; TC: Total Citations; CPP: Citations Per Paper; HI: h-index; ICP: International Collaborative Papers; RCI: Relative Citation Index

\section{Profile of top 15 most productive authors}

In the field of Indian rheumatoid arthritis research, the research productivity of top 15 most productive authors varied from 13 to 60 publications. Together they contributed 18.23\% (318) Indian publication share and 22.36\% (3601) citation share during 200716. The scientometric profile of these 15 authors is presented in (Table 5). Five authors registered publications output above the group average of 21.2: Aggarwal AA (60 papers), Misra R (33 papers), Chopra A (29 papers), Agarwal V and Danda D (22 papers each) during 2007-16. Five authors registered impact above the group average of 11.32 citations per publication: Misra R (17.94),

Aggarwal AA (17.65), Chopra A (14.86), Ghosh A (13.69) and Gupta $\mathrm{R}$ (11.75) during 2007-16. Five authors registered h-index above the group average of 7.53 of all authors: Aggarwal AA (19), Misra R (14), Chopra A (11), Gupta R (9) and Agarwal V (8) during 2007-16. Eight authors contributed international collaborative publications share above the group average of $15.72 \%$ of all authors: Handa R (42.86\%), Ravindran V (29.41\%), Dhir V (23.08\%), Danda D (22.73\%), Shankar S (21.43\%), Aggarwal AA (18.33\%), Chopra A (17.24\%) and Kumar A (15.78\%) during 2007-16. Five authors registered the relative citation index above the group average (1.23) of all authors: Misra R (1.94), Aggarwal AA (1.91), Chopra A (1.61), Ghosh A (1.48) and Gupta R (1.27) during 2007-16.

Table 5: Scientometric profile of top 15 most productive authors in rheumatoid arthritis research during 2007-16.

\begin{tabular}{|c|c|c|c|c|c|c|c|c|c|}
\hline S.No & Name of the Author & Affiliation of the Author & TP & TC & CPP & HI & ICP & $\%$ ICP & RCI \\
\hline 1 & Aggarwal AA & SGPGIMS, Lucknow & 60 & 1059 & 17.65 & 19 & 11 & 18.33 & 1.91 \\
\hline 2 & Misra R & SGPGIMS, Lucknow & 33 & 592 & 17.94 & 14 & 2 & 6.06 & 1.94 \\
\hline 3 & Chopra A & $\begin{array}{c}\text { Centre for Rheumatic Diseases, } \\
\text { Pune }\end{array}$ & 29 & 431 & 14.86 & 11 & 5 & 17.24 & 1.61 \\
\hline 4 & Danda D & CMC, Vellore & 22 & 72 & 3.27 & 5 & 5 & 22.73 & 0.35 \\
\hline 5 & Kumar A & $\begin{array}{l}\text { Fortis Flt. Lt. Rajan Dhall Hospital, } \\
\text { New Delhi }\end{array}$ & 19 & 174 & 9.16 & 7 & 3 & 15.79 & 0.99 \\
\hline 6 & Ravindran V & Center for Rheumatology, Calicut & 17 & 51 & 3 & 4 & 5 & 29.41 & 0.33 \\
\hline 7 & Gupta R & AIIMS, New Delhi & 16 & 188 & 11.75 & 9 & 2 & 12.5 & 1.27 \\
\hline 8 & Silakari 0 & Punjabi University, Patiala & 16 & 151 & 9.44 & 7 & 0 & 0 & 1.02 \\
\hline 9 & Singh S & PGIMER, Chandigarh & 16 & 73 & 4.56 & 5 & 1 & 6.25 & 0.49 \\
\hline 10 & Handa R & AIIMS, New Delhi & 14 & 120 & 8.57 & 5 & 3 & 21.43 & 0.93 \\
\hline 11 & Malaviya AN & Indian Spinal Injury Centre, Delhi & 14 & 119 & 8.5 & 6 & 6 & 42.86 & 0.92 \\
\hline 12 & Shankar S & AIIMS, New Delhi & 14 & 62 & 4.43 & 4 & 2 & 14.29 & 0.48 \\
\hline 13 & Dhir V & AIIMS, New Delhi & 13 & 178 & 13.69 & 5 & 2 & 15.38 & 1.48 \\
\hline \multirow[t]{4}{*}{14} & Ghosh A & IPMER, Kolkata & 13 & 114 & 8.77 & 4 & 3 & 23.08 & 0.95 \\
\hline & & Total of 15 authors & 318 & 3601 & 11.32 & 7.53 & 50 & 15.72 & 1.23 \\
\hline & & Total of India & 1744 & 16104 & 9.23 & & & & \\
\hline & & $\begin{array}{c}\text { Share of top } 15 \text { authors in Indian } \\
\text { total output }\end{array}$ & 18.23 & 22.36 & & & & & \\
\hline
\end{tabular}

TP: Total Papers; TC: Total Citations; CPP: Citations Per Paper; HI: h-index; ICP: International Collaborative Papers; RCI: Relative Citation Index

\section{Medium of communication}

Of the total Indian output in rheumatoid arthritis research, 98.74\% (1722) appeared in journals. The top 15 most productive journals accounted for 15 to 169 papers each in arthritis research and together accounted for $31.24 \%$ share (538 papers) of total journal publication output during 2007-16. The publication share of these top 15 most productive journals increased from $30.41 \%$ to $31.79 \%$ from $2007-11$ and $2012-16$. The top most productive journal (with 169 papers) was Indian Journal of Radiology, followed by International Journal of Rheumatic Diseases (50 papers), Rheumatology International (36 papers), Clinical Rheumatology (30 papers), etc. during 2007-16 (Table 6) [6-10].

Table 6: Top 15 most productive journals in indian rheumatoid arthritis research during 2007-2016.

\begin{tabular}{|c|c|c|c|c|}
\hline \multirow{2}{*}{ S.No } & Name of the Journal & \multicolumn{2}{|c|}{ Number of Papers } \\
\cline { 3 - 4 } & & $\mathbf{2 0 0 7 - 1 1}$ & $\mathbf{2 0 1 2 - 1 6}$ & 82 \\
\hline 1 & Indian Journal of Radiology & 87 & 169 \\
\hline
\end{tabular}




\begin{tabular}{|c|c|c|c|c|}
\hline 2 & $\begin{array}{l}\text { International Journal of Rheumatological } \\
\text { Diseases }\end{array}$ & 13 & 37 & 50 \\
\hline 3 & Rheumatology International & 13 & 23 & 36 \\
\hline 4 & Clinical Rheumatology & 18 & 16 & 34 \\
\hline 5 & Indian Journal of Pediatrics & 15 & 15 & 30 \\
\hline 6 & $\begin{array}{l}\text { International Journal of Pharmacy \& } \\
\text { Pharmaceutical Sciences }\end{array}$ & 4 & 25 & 29 \\
\hline 7 & $\begin{array}{l}\text { International Journal of Pharmaceutical } \\
\text { Sciences Review and Research }\end{array}$ & 7 & 20 & 27 \\
\hline 8 & $\begin{array}{l}\text { International Journal of Pharma \& Bio } \\
\text { Sciences }\end{array}$ & 7 & 17 & 24 \\
\hline 9 & Journal of Clinical \& Diagnostic Research & 2 & 21 & 23 \\
\hline 10 & $\begin{array}{l}\text { Research Journal of Pharmaceutical Biological } \\
\text { \& Chemical Sciences }\end{array}$ & 7 & 16 & 23 \\
\hline 11 & Journal of Rheumatology & 16 & 6 & 22 \\
\hline 12 & $\begin{array}{c}\text { Asian Journal of Pharmaceutical \& Chemical } \\
\text { Research }\end{array}$ & 2 & 18 & 20 \\
\hline 13 & Journal of Association of Physicians of India & 7 & 12 & 19 \\
\hline 14 & BMJ Case Reports & 0 & 17 & 17 \\
\hline \multirow[t]{4}{*}{15} & $\begin{array}{l}\text { Indian Journal of Dermatology, Venereology \& } \\
\text { Leprology }\end{array}$ & 10 & 5 & 15 \\
\hline & Total of 15 journals & 208 & 330 & 538 \\
\hline & Total global journal output & 684 & 1038 & 1722 \\
\hline & $\begin{array}{c}\text { Share of top } 15 \text { journals in Indian journal } \\
\text { output }\end{array}$ & 30.41 & 31.79 & 31.24 \\
\hline
\end{tabular}

\section{Highly cited papers}

A total of 12 highly cited papers were identified which received citations from 101 to 1138 during 2007-16. These 12papers together received 3405 citations, which averaged to 283.78 citations per paper. Of the 12 high cited papers, 7 were reviews and 5 articles. Seven out of 12 high cited papers involve collaboration (2 national collaborative and 5 international collaborative).These 12 high cited papers involve the participation of 263 authors and 228 organizations (26 Indian). The 26 Indian organizations include 2 papers in Sanjay Gandhi Postgraduate Institute of Medical Sciences, Lucknow and 1 paper each in All India Institute of Medical Sciences, New Delhi, Postgraduate Institute of Medical Education \& Research, Chandigarh, Jamia Hamdard, Delhi, etc. These 12 highly cited papers were published in 12 journals such as Arthritis Research \& Therapy, Colloid and Surface B, Current Problems in Cancer, Drug Discovery Today, European Journal of Pharmaceutical Sciences, Journal of American Medical Association, Journal of Clinical Pharmacology, Journal of Rheumatology, The Lancet, Medicinal Research Review, and Mini Reviews in Medicinal Chemistry and Seminars in Nuclear Medicine.

\section{Conclusion}

India has published 1744 publications in rheumatoid arthritis research during 2007-16, increasing from92 in the year 2007 to 1658 publications in the year 2016, 8.19\% growth per annum. The cumulative Indian output in rheumatoid arthritis research increased from 687 to 1057 publications from 2007-11 to 201216 , registering $53.86 \%$ growth. India's share in global output was
$3.54 \%$ during $2007-16$, which increased from $2.96 \%$ to $4.09 \%$ from 2007-11 to 2012-16. India's share in global publication output in rheumatoid arthritis was 3.05\% during 2007-16, which increased from $2.46 \%$ to $3.61 \%$ from $2007-11$ to $2012-16$. The average citation impact per paper of Indian publications on rheumatoid arthritis research was 9.23 citations, which decreased from 14.62 to 5.73 from $2007-11$ to $2012-16$.The international collaborative share of India's publications in rheumatoid arthritis research was $11.75 \%$ during $2007-16$, which decreased from $12.02 \%$ to $11.75 \%$ from 2007-11 to 2012-16. USA contributed the largest share of $47.80 \%$ to India's international collaborative papers in rheumatoid arthritis research, followed by U.K. (22.44\%), France (12.20\%), Germany (10.24\%), Japan (9.76\%), Italy and Netherlands $(7.80 \%$ each), Canada and Sweden (7.32\% each) and Argentina (6.83\%) during 2007-16.

Medicine, among subjects contributed the highest publications share $(58.89 \%)$ in India's output in rheumatoid arthritis, followed by pharmacology, toxicology \& pharmaceutics (30.91\%), biochemistry, genetics \& molecular biology (18.41\%), immunology \& microbiology (12.10\%) and chemistry (3.44\%) during 200716. The research activities showed increase in pharmacology, toxicology \& pharmaceutics, biochemistry, genetics \& molecular biology, immunology \& microbiology and chemistry, as against decline in medicine from 2007-11 to 2012-16.

The top 15 most productive organizations and authors together contributed $29.87 \%$ and $18.23 \%$ respectively as their share of global publication output and $37.92 \%$ and $22.36 \%$ respectively as 
their share of global citation output during 2007-16. The leading organizations in terms of publication productivity were: Sanjay Gandhi Postgraduate Institute of Medical Sciences, Lucknow (87 papers), All India Institute of Medical Sciences, New Delhi (80 papers), Postgraduate Institute of Medical Education \& Research, Chandigarh (76 papers), Christian Medical College, Vellore (38 papers), etc. during 2007-16. The leading organizations in terms of research quality and impact (measured in terms of citations per paper) were All India Institute of Medical Sciences, New Delhi (20.35), Center for Rheumatic Diseases, Pune (17.40), Postgraduate Institute of Medical Education \& Research, Chandigarh (15.68), Aligarh Muslim University (15.41), Sanjay Gandhi Postgraduate Institute of Medical Sciences, Lucknow (13.51) and Banaras Hindu University, Varanasi (13.0), etc. during 2007-16.

Among the total journal output of 1722 papers $(98.74 \%$ of total output), the top 15 journals contributed $31.24 \%$ share to the global journal output during 2007-16 which increased from $30.41 \%$ to $31.79 \%$ from $2007-11$ and $2012-16$. Indian Journal of Radiology (with 169 papers) contributed the largest number of papers, followed by International Journal of Rheumatic Diseases (50 papers), Rheumatology International (36 papers), Clinical Rheumatology (30 papers), etc. during 2007-16. Only 12 highly cited publications registered citations from 101 to 1138 in rheumatoid arthritis research and they together received 3405 citations, with 283.78 citations per paper. These 12 high cited papers involve the participation of 263 authors and 228 organizations (26 Indian) These 12 highly cited papers were published in 12 journals, with 1 paper each in Arthritis research \& therapy, colloid and surface b, current problems in cancer, drug discovery today, European journal of pharmaceutical sciences, journal of American medical association, journal of clinical pharmacology, journal of rheumatology, the lancet, medicinal research review, mini reviews in medicinal chemistry and seminars in nuclear medicine.
Concludes that rheumatology has been a neglected subspecialty in India. A staggering patient load, a severely inadequate number of trained rheumatology specialists, therapeutic nihilism and limited advocacy are some of the critical challenges that confront rheumatology care, and possibly explain the high rates of reliance on complementary and alternative medicines in India. To address the many problems with rheumatology care in India, curricular reforms, capacity building, patient education and political support are sorely needed.

\section{References}

1. Arthritis Foundation. What is Rheumatoid arthritis?

2. Global, regional, and national incidence, prevalence, and years lived with disability for 310 diseases and injuries (1990-2015) A systematic analysis for the global burden of disease study 2015. Lancet 8 9388(10053): 1545-1602.

3. Smolen, Josef S, Aletaha, Daniel, McInnes, et al. (2016) Rheumatoid arthritis. Lancet 22388 (10055): 2023-2038.

4. (2014) Handout on health: rheumatoid arthritis. National Institute of Arthritis and Musculoskeletal and Skin Diseases.

5. Global, regional, and national age-sex specific all-cause and cause-specific mortality for 240 causes of death, 1990-2013: a systematic analysis for the global burden of disease study 2013. Lancet 17 385(9963): 117-171.

6. Arthritis-India (2014) Rheumatoid arthritis. 2014.

7. Lewison, Grant, Devey ME (1999) Bibliometric methods for the evaluation of arthritis research. Rheumatology 38: 13-20.

8. Gupta BM, Ahmed M, Gupta KK, Ritu (2017) Arthritis research in india: a scientometric assessment of publications output during 2007-16. SciFed Orthopedics \& Rheumatology Journal 1(1): 1-10.

9. Handa, Rohini R, Lewis URL, Juliana FM, Gautam R, et al. (2016) Literature review of rheumatoid arthritis in India. International Journal of Rheumatic Diseases 19(5): 440-451.

10. Kumar A, Sapna G, Ritu G, Gupta BM (2017) Osteoarthritis research in India: A scientometric assessment of publications output during 200716. International Journal of Information Dissemination and Technology 7(3): 157-161.
Creative Commons Attribution 4.0 International License

For possible submissions Click Here
Submit Article

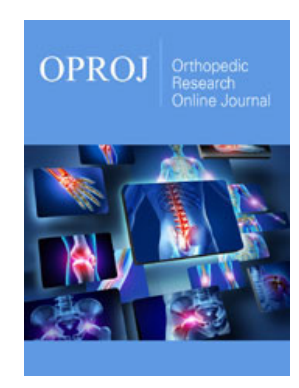

Orthopedic Research Online Journal

\section{Benefits of Publishing with us}

- High-level peer review and editorial services

- Freely accessible online immediately upon publication

- Authors retain the copyright to their work

- Licensing it under a Creative Commons license

- Visibility through different online platforms 